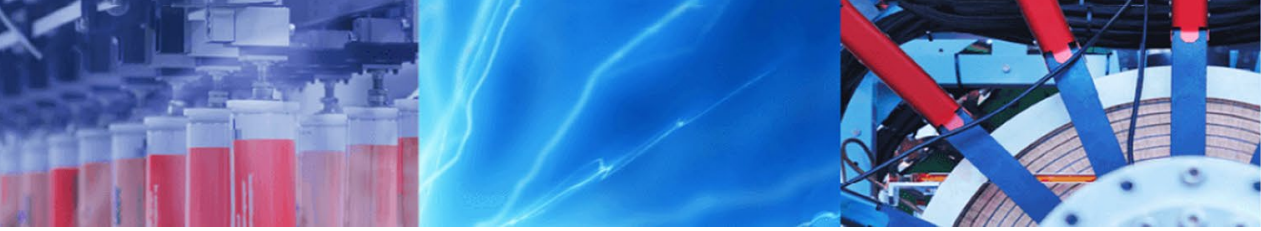

Research Article

\title{
A modified QuEChERS/GC-MS for simultaneous determination of 16 pesticide adjuvant residues in fruits and vegetables
}

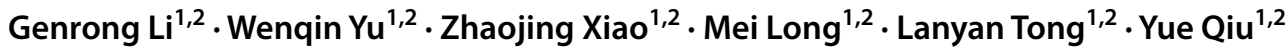

Received: 12 August 2019 / Accepted: 13 November 2019 / Published online: 6 December 2019

(c) Springer Nature Switzerland AG 2019

\begin{abstract}
A rapid, sensitive, and practical QuEChERS method coupled with gas chromatography-mass spectrometry was developed for the simultaneous determination of 16 chemical adjuvant residues in samples of fruits (apple, nectarine, grape) and vegetables (tomato, cucumber, spinach). All target compounds were separated in less than $16 \mathrm{~min}$. Samples were extracted with acetonitrile, and the types of extraction salt and cleanup sorbent were optimized. The optimized method was validated by evaluating the linearity, accuracy, precision, and matrix effect. The recoveries of the 16 pesticides adjuvants ranged from 61.2 to $116.3 \%$ with relative standard deviations lower than $11.6 \%$. Limits of detection ranged from 0.21 to $3.02 \mu \mathrm{g} / \mathrm{kg}$, and limits of quantification ranged from 0.71 to $10.07 \mu \mathrm{g} / \mathrm{kg}$. Finally, the developed method was successfully employed to identify and quantify pesticide adjuvant residues in the analysis of 30 real fruit and vegetable samples.
\end{abstract}

Keywords GC-MS · QuEChERS · Pesticide adjuvant · Residue · Fruit · Vegetable

\section{Introduction}

Chemical adjuvants are used in various industries. The main sources of chemical adjuvant pollution from vegetables and fruits are air pollution and road dust, but the most important pollution is caused by pesticides [1]. Commercial formulations of pesticides are composed of a designated pesticidal "active principle" and "other ingredients," with the latter as any substance other than the "active principle" that intentionally added to a pesticide product. The inactive other ingredients are also called pesticide adjuvant, including emulsifiers, solvents, surfactants, dyes, and so on [1]. The commonly used pesticide adjuvants are more than 3000 varieties, and their contents in pesticide formulations can reach up to $99 \%$ [2]. Pesticide adjuvants are mistaken for "inert" additives that are not harmful to the environment or human health. However, studies have shown that some considered "inert" adjuvants are even more toxic than the active ingredients [3-6]. Séralini compared toxicity on human cells of glyphosate alone, major adjuvant alone, and a total formulation. The results showed that the toxicity of adjuvant alone was the greatest, and the toxicity was proportional to the concentration of adjuvant [3]. Mansano found that commercial product carbofuran was more toxic than its pure form on Paramecium caudatum [6]. On the basis of extensive research and comprehensive assessment, China has included benzene,

Electronic supplementary material The online version of this article (https://doi.org/10.1007/s42452-019-1677-8) contains supplementary material, which is available to authorized users.

Genrong Li and Wenqin Yu have contributed equally to this paper.

$\triangle$ Wenqin Yu, kathy198813@126.com | 'Chongqing Academy of Metrology and Quality Inspection, Chongqing 401123, People's Republic of China. ${ }^{2}$ Inspection on Agricultural Processed Products and Condiments, Chongqing 401123, People's Republic of China. 
trichloroethylene, 4-methyl-2-pentanone, toluene, 2-hexanone, tetrachloroethylene, chlorobenzene, ethyl benzene, xylenes, 1,2-dichlorobenzene, isophorone, naphthalene, diphenyl ether, and tributyl phosphate in its "prohibited and restricted lists of pesticide adjuvants" and limited their contents in pesticide formulations to $0.1 \%(\mathrm{w} / \mathrm{w})$ for diphenyl ether, $2 \%(\mathrm{w} / \mathrm{w})$ for ethyl benzene, $10 \%(\mathrm{w} / \mathrm{w})$ for xylenes, and $1 \%(\mathrm{w} / \mathrm{w})$ for others mentioned above [7]. Most of the mentioned 16 pesticide adjuvants are of high toxicity, and benzene, trichloroethylene, 4-methyl-2-pentanone, toluene, tetrachloroethylene, ethyl benzene, xylenes, and naphthalene are on the newly published list of human carcinogens by the International Agency for Research on Cancer (IARC) [8].

Imperfect management leads to the abuse of pesticide adjuvants, which seriously endangers the environment, human, and animal health [9-13]. In recent years, studies have shown that pesticide adjuvants are found in human samples and even in children [14-16]. Therefore, people have to pay attention to pesticide adjuvant residues in agricultural products that are most directly related to pesticides. To date, several methods have been developed for determining of benzene series [17], alkyl phenols [18, 19], pyrrolidone [13, 20], and organosilicon [21, 22], including gas chromatography, GC-MS, liquid chromatography-tandem mass spectrometry (LC-MS/MS). However, there is still sparse information on the residue levels of the above-mentioned pesticide adjuvants included in the list of "prohibited and restricted lists of pesticide adjuvants" in agroproducts, and it is still a challenge to explore an analytical method for the simultaneous determination of it in a single chromatographic run. GC-MS is a powerful and efficient tool for the analysis of organic pollutants, because of its strong anti-interference ability, high accuracy, and sensitivity.

The "quick, easy, cheap, effective, rugged, and safe" (QUEChERS) solid-phase extraction approach was introduced in 2003 for sample pretreatment [23]. It has demonstrated wide application in analysis of pesticide residues in a variety of matrices. So far, the QuEChERS approach has not been applied for the simultaneous determination of the 16 pesticide adjuvants mentioned above. The present study was to develop and validate a new QuEChERS method coupled with GC-MS for the simultaneous determination of the 16 pesticide adjuvants in fruits (apple, nectarine, grape) and vegetables (spinach, tomato, cucumber). Firstly, the type and amount of extraction salt and cleanup sorbent of QuEChERS method were optimized to achieve the maximum extraction efficiencies for 16 pesticide adjuvants. Next, the key parameters of GC-MS were discussed. Finally, sensitivity, precision, accuracy, matrix effect (ME), and practicability of the optimized method were evaluated.

SN Applied Sciences

\section{Materials and methods}

\subsection{Reagents and materials}

Acetonitrile (HPLC grade) was obtained from Fisher Scientific (Pittsburg, PA, USA). 4-Methyl-2-pentanone (AR, 99\%), 1,2-dichlorobenzene (AR, 99\%), ethyl benzene (anhydrous, 99.8\%), diphenyl ether (GC, 99\%), tributyl phosphate (AR, $\geq 99 \%)$, tetrachloroethylene (GR, 99.5\%), 2-hexanone (AR, 99\%), chlorobenzene (AR, 99.5\%), and benzene (AR, 99\%) were provided by Aladdin (Shanghai, China); isophorone (AR, 99\%), p-xylene (GC, $\geq 99 \%$ ), naphthalene (GC, $\geq 99.5 \%)$, m-xylene (GC, $>99 \%)$, and toluene $(A R, \geq 99.5 \%)$ were supplied by Macklin Reagent (Shanghai, China); trichloroethylene (GR, 99.5\%) was purchased from Xiya Reagent (Shandong,China); O-xylene $(99 \%+)$ was provided by Adamas Reagent (Shanghai, (hina).

Anhydrous magnesium sulfate ( $\left.\mathrm{Anh} . \mathrm{MgSO}_{4}\right)$, anhydrous sodium sulfate (Anh. $\mathrm{Na}_{2} \mathrm{SO}_{4}$ ), anhydrous sodium acetate (Anh. $\mathrm{NaAc})$, and sodium chloride $(\mathrm{NaCl})$ were analytical grade from Aladdin (Shanghai, China). Cleanert C18 (40-50 $\mu \mathrm{m}, 60 \AA$ pore size) and primary secondary amine (PSA, 40-70 $\mu \mathrm{m}, 60 \AA$ ) were from Ji'nan Bona Biological Technology Co., Ltd (Shandong China). Graphitized carbon black (GCB) and magnesium trisilicate (Florisil) were purchased from Welch Materials, Inc. (Shanghai China). To ensure efficient removal of any studied analytes and residual water, $\mathrm{MgSO}_{4}, \mathrm{NaCl}$, and $\mathrm{Na}_{2} \mathrm{SO}_{4}$ were treated at $500^{\circ} \mathrm{C}$ for $2 \mathrm{~h}$ in muffle furnace, $\mathrm{NaAc}$ and all adsorbents mentioned above were treated at $200^{\circ} \mathrm{C}$ for at least $4 \mathrm{~h}$ in drying oven and then kept in a desiccator before use.

Individual stock solutions of $1.0 \mathrm{mg} / \mathrm{mL}$ for 16 pesticide adjuvants were prepared in ACN and stored in the dark at $-18{ }^{\circ} \mathrm{C}$. The 16 standard solutions were mixed and diluted with $\mathrm{ACN}$ daily to prepare a series of working solutions for sample fortification and calibration curves.

\subsection{Sample preparation}

Spinach, tomato, cucumber, apple, nectarine, and grape were purchased from local market in Chongqing (China). Samples were chopped and homogenized (IKA-Werke, Staufen, Germany) without washing and stored at $-20^{\circ} \mathrm{C}$ refrigerator storage until use. For all spiked experiments, samples were pre-screened to confirm that they are free from the target compounds.

A representative portion of each sample $(10.0 \mathrm{~g})$ was weighed into a $50-\mathrm{mL}$ polypropylene centrifuge tube. For the spiked experiment, appropriate amount 
of working standard solution was added to the blank sample. The spiked samples were vortexed for $30 \mathrm{~s}$ and equilibrated at room temperature for $2 \mathrm{~h}$ to evenly distribute the pesticide adjuvants. After that, $10 \mathrm{~mL} \mathrm{ACN}$ was added into the sample. The mixtures were vortexed for $1 \mathrm{~min}$ followed by the addition of $6.0 \mathrm{~g} \mathrm{MgSO}_{4}$ and $1.5 \mathrm{~g} \mathrm{NaAc}$. The mixtures were shaken immediately vigorously for $1 \mathrm{~min}$ in ice bath to prevent formation of $\mathrm{MgSO}_{4}$ conglomerates and then centrifuged (Biofuge Stratos, Heraeus, Germany) for $5 \mathrm{~min}$ at $6000 \mathrm{rpm}$ (3743 rcf) in order to obtain good separation of the organic phase and the aqueous phase. Next, a portion of supernatant fluid $(5 \mathrm{~mL})$ was transferred into a $15-\mathrm{mL}$ centrifuge tube containing the sorbents (200 mg PSA and $1200 \mathrm{mg} \mathrm{MgSO}_{4}$ ). Each tube was vortexed for $1 \mathrm{~min}$ and centrifuged for $5 \mathrm{~min}$ at $8000 \mathrm{rpm}$ (6654 rcf). Finally, the supernatant was filtered through a $0.22-\mu \mathrm{m}$ filtration membrane into a glass autosampler vial (Agilent, USA) for GC-MS analysis. To make sure the accuracy of measurement, procedural blank and solvent blank were done each batch.

\subsection{GC-MS analysis}

GC-MS analysis was performed using an Agilent 7890A gas chromatography (GC) instrument equipped with a 5977C mass selective detector (MS) (Agilent technologies, USA). Chromatographic separation was carried out using a HP-5ms capillary column ( $30 \mathrm{~m} \times 250 \mu \mathrm{m}$ i.d., $0.25 \mu \mathrm{m}$ thickness; Agilent, USA). The oven temperature was held at $38^{\circ} \mathrm{C}$ for $3 \mathrm{~min}$, followed by a temperature ramp at $5^{\circ} \mathrm{C} /$ min to $50^{\circ} \mathrm{C}$, held for $2 \mathrm{~min}$, then increased at $50^{\circ} \mathrm{C} / \mathrm{min}$ to $150^{\circ} \mathrm{C}$, held for $2 \mathrm{~min}$, and a final increased at $15^{\circ} \mathrm{C} / \mathrm{min}$ to $200^{\circ} \mathrm{C}$, held for $2 \mathrm{~min}$. Helium carrier gas (purity $\geq 99.999 \%$ ) was maintained at a constant flow rate of $1.0 \mathrm{~mL} / \mathrm{min}$. For analysis, $1 \mu \mathrm{L}$ of the extract was injected into the GC/MS system in a split injection mode (split ratio 20:1) using the autosampler. The temperature of the inlet, ion source, and quadrupole were 200,230 , and $150^{\circ} \mathrm{C}$, respectively. While the MS transfer line was maintained at $280^{\circ} \mathrm{C}$. The mass spectrometer was operated with an electron impact (EI) ionization by selective ion monitoring (SIM) modes. The retention time, quantitative and qualitative ions of 16 pesticide adjuvants are shown in Table 1.

\subsection{Method validation}

To ensure the reliability and accuracy of the developed method, the linearity, ME, accuracy, precision, limit of detection (LOD), and limit of quantitation (LOQ) were evaluated. Linearity of the method was investigated by determining a series of mixed working standard solutions $(10.0,20.0,50.0,100.0,200.0,500.0$, and $1000.0 \mu \mathrm{g} / \mathrm{L})$ of 16 pesticide adjuvants. ME was evaluated by comparison of calibration curves in ACN (standard calibration) with calibration curves in blank extract of vegetables (spinach,

Table 1 Retention time (RT, $\mathrm{min}), \mathrm{GC}-\mathrm{MS}$ parameter, linear equation, coefficient of determination $\left(R^{2}\right)$, standard deviation of the slope $\left(\mathrm{S}_{\mathrm{b}}\right)$ and intercept $\left(S_{a}\right)$, limit of detection (LOD, $\left.\mu \mathrm{g} / \mathrm{kg}\right)$, and limit of quantification $(L O Q, \mu \mathrm{g} / \mathrm{kg})$ for 16 analytes in $A C N$

\begin{tabular}{|c|c|c|c|c|c|c|c|c|c|}
\hline Analyte & RT (min) & Quantitative ion & Qualitative ion & Linear regression & $R^{2}$ & $S_{b}$ & $S_{a}$ & LOD $(\mu \mathrm{g} / \mathrm{kg})$ & $\overline{L O Q}(\mu \mathrm{g} / \mathrm{kg})$ \\
\hline Benzene & 2.99 & 78 & 77,52 & $y=72.59 x+468.78$ & 0.9994 & 0.7631 & 329.2345 & 1.40 & 4.66 \\
\hline $\begin{array}{l}\text { Trichloroethyl- } \\
\text { ene }\end{array}$ & 3.58 & 129.9 & $131.9,96.9$ & $y=25.96 x+144.85$ & 0.9997 & 0.1857 & 80.1267 & 0.35 & 1.17 \\
\hline $\begin{array}{l}\text { 4-Methyl-2-pen- } \\
\text { tanone }\end{array}$ & 4.45 & 43 & 58,85 & $y=21.53 x+114.83$ & 0.9997 & 0.1694 & 73.1025 & 0.69 & 2.29 \\
\hline Toluene & 5.06 & 91 & 92,65 & $y=67.99 x+599.75$ & 0.9995 & 0.7075 & 305.2361 & 3.02 & 10.07 \\
\hline 2-Hexanone & 5.70 & 43 & 58,85 & $y=28.50 x+28.67$ & 0.9998 & 0.1191 & 51.3706 & 0.67 & 2.23 \\
\hline $\begin{array}{l}\text { Tetrachloroeth- } \\
\text { ylene }\end{array}$ & 6.12 & 165.9 & $163.9,128.9$ & $y=38.46 x+195.86$ & 0.9997 & 0.2916 & 125.8104 & 0.76 & 2.54 \\
\hline Chlorobenzene & 7.62 & 112 & 77,114 & $y=74.94 x+385.08$ & 0.9997 & 0.5963 & 257.2869 & 0.55 & 1.84 \\
\hline Ethylbenzene & 7.99 & 91 & 106,77 & $y=79.28 x+564.02$ & 0.9996 & 0.6973 & 300.8313 & 1.07 & 3.56 \\
\hline m,p-Xylene & 8.20 & 91 & 106,77 & $y=66.71 x+558.40$ & 0.9994 & 0.7270 & 313.6486 & 1.02 & 3.40 \\
\hline o-Xylene & 8.54 & 91 & 106,77 & $y=64.09 x+449.64$ & 0.9996 & 0.5398 & 232.9083 & 0.88 & 2.92 \\
\hline $\begin{array}{l}\text { 1,2-Dichlo- } \\
\text { robenzene }\end{array}$ & 9.93 & 145.9 & $147.9,111$ & $y=57.28 x-408.81$ & 0.9981 & 1.1128 & 480.0873 & 0.53 & 1.75 \\
\hline Isophorone & 10.58 & 82 & $138.1,54$ & $y=32.38 x-168.62$ & 0.9965 & 0.8587 & 370.4810 & 0.24 & 0.79 \\
\hline Naphthalene & 11.14 & 128 & 129,127 & $y=102.42 x-648.85$ & 0.9998 & 0.6731 & 290.4079 & 1.30 & 4.34 \\
\hline Diphenyl ether & 13.12 & 170 & 141,51 & $y=71.15 x+556.98$ & 0.9992 & 0.8838 & 381.2910 & 0.34 & 1.12 \\
\hline $\begin{array}{l}\text { Tributyl phos- } \\
\text { phate }\end{array}$ & 15.10 & 99 & 155,211 & $y=41.31 x+41.19$ & 0.9999 & 0.0993 & 42.8451 & 0.21 & 0.71 \\
\hline
\end{tabular}


tomato, cucumber) and fruits (apple, nectarine, grape) by the equation of ME $(\%)=$ (slope of matrix-matched calibration curve - slope of solvent-based calibration curve)/ (slope of solvent-based calibration curve) $\times 100$ [24]. Accuracy (expressed as recovery) and precision (expressed as $\mathrm{RSD}$ ) of the method were determined on blank matrices $(n=6)$ spiked at $0.1,0.2$, and $0.5 \mathrm{mg} / \mathrm{kg}$ of all the analytes.

\section{Results and discussion}

\subsection{Optimization of extraction and cleanup procedure}

The extraction efficiency largely depends on the nature of the sample and the physicochemical properties of the residual pesticide adjuvants. Vegetables and fruits are very complex matrices and contain a variety of interfering components, such as sugars, pigments, organic acids, sterols, and alkaloids. To minimize or eliminate co-extraction of these matrix interferences, we chose to use $A C N$ as the extraction solvent because ACN had the fewest possible interfering peaks in GC/MS both before and after cleanup procedures [23]. The original unbuffered QuEChERS method was used with slight modifications to adjust to a specific application of detection pesticide adjuvants by adjusting extraction salts and sorbents formulations of the cleanup steps.

\subsubsection{Optimization of extraction procedure}

In QuEChERS extraction procedure with $\mathrm{ACN}$, the effects of $\mathrm{NaAc}$ and traditional $\mathrm{NaCl}$ combined with two common dehydrating agents $\mathrm{MgSO}_{4}$ and $\mathrm{Na}_{2} \mathrm{SO}_{4}$ were compared. The recoveries of target compound in the four combination modes shown in Fig. 1 were compared at spiking level of $0.2 \mathrm{mg} / \mathrm{kg}$ with three replicates. Studies show that the 4:1 salt ratio is most effective in separating the aqueous and organic phases, maintaining high recoveries and low interference co-extraction [25]. This study also uses this ratio. In this experiment, the same extraction conditions but for different combinations of extract salt as shown in Sect. 2.2 and no cleanup steps were used, so the influence of purifying agent was excluded.

In Fig. 1, the results showed that the recovery of most pesticide adjuvants was not significantly affected by different salt combinations. Compared with $\mathrm{Na}_{2} \mathrm{SO}_{4}, \mathrm{MgSO}_{4}$ provided the most complete liquid-liquid-phase separation and was better able to bind large amounts of water with lower price [25]. There was no significant difference between $\mathrm{NaCl}$ and $\mathrm{NaAc}$ on the recovery of the target analytes because they are all neutral compounds. Therefore, both of them can meet the analysis requirements.
However, in order to apply this method to analyze more different types of pesticide adjuvants in the future, $\mathrm{NaAC}$ is selected as the extraction salt. In this way, acetic acid can be added to form a buffer system to inhibit the decomposition of acid-sensitive compounds, the same as AOAC Official Method 2007.01 developed by Lehotay [26], which have been adopted as routine methods in many laboratories. So we choose $\mathrm{MgSO}_{4}$ and $\mathrm{NaAC}$ as extraction salt.

\subsubsection{Optimization of cleanup procedure}

The choice of the desired adsorbent was based on the determination of the co-extracted by the adsorbent as evaluated in the ACN extract. With the aim to achieve efficient removal of the diverse matrix interferences in samples, we evaluated the effect of different cleaning sorbents combinations. $\mathrm{C} 18+\mathrm{MgSO}_{4}, \mathrm{PSA}+\mathrm{MgSO}_{4}, \mathrm{GCB}+\mathrm{MgSO}_{4}$, and Florisil $+\mathrm{MgSO}_{4}$ were investigated in the cleanup procedure regarding recoveries of the 16 analytes in samples spiked at $0.2 \mathrm{mg} / \mathrm{kg}$ with three replicates while keeping the other parameters constant as Sect. 2.2 described. $\mathrm{MgSO}_{4}$ was added for drying of the ACN phase, and it reduced the polar ACN extract and prevented the residual water from affecting the cleanup process and GC separation.

As Fig. 2 shows, the combination of PSA and $\mathrm{MgSO}_{4}$ displayed better cleaning up efficiency with the optimal recoveries of target analytes. Both C18 Florisil and GCB failed to obtain satisfactory results. Although GCB has a good adsorption effect on planar molecules such as pigments [23], sterols, and other nonpolar interferences, it also retains targeted planar compounds or aromatic compounds such as naphthalene, 1,2-dichlorobenzene, and chlorobenzene and caused low recoveries for them $(<73.0 \%)$; recovery of naphthalene in all studied matrices is only $23.4-37.9 \%$. When using C18 and Florisil, there was significantly matrix enhancement, especially in high pigment matrices such as spinach and grape. Overall, PSA along with $\mathrm{MgSO}_{4}$ showed the best performance and all the 16 pesticide adjuvants had the acceptable recoveries (63.0-122.5\%). PSA did not retain the pesticide adjuvants, but it effectively removed polar interferences such as sugars, pigments, fatty acids, and other organic acids. Furthermore, due to the rapid formation of hydrogen bonds, PSA purification was quickly completed within a few seconds [23]. So PSA along with $\mathrm{MgSO}_{4}$ were effective in separating pesticide adjuvants and maximally adsorbing matrix coextracts because PSA contains both primary and secondary amines [27]. Thus, $\mathrm{MgSO}_{4}$ and PSA were finally chosen as the sorbents of the cleanup method.

Next, spinach and grape with high pigment content were selected as the representative matrix, and the effect of different amount of PSA on the recovery of 16 pesticide adjuvants was optimized at spiking level of $0.2 \mathrm{mg} / \mathrm{kg}$ with three 

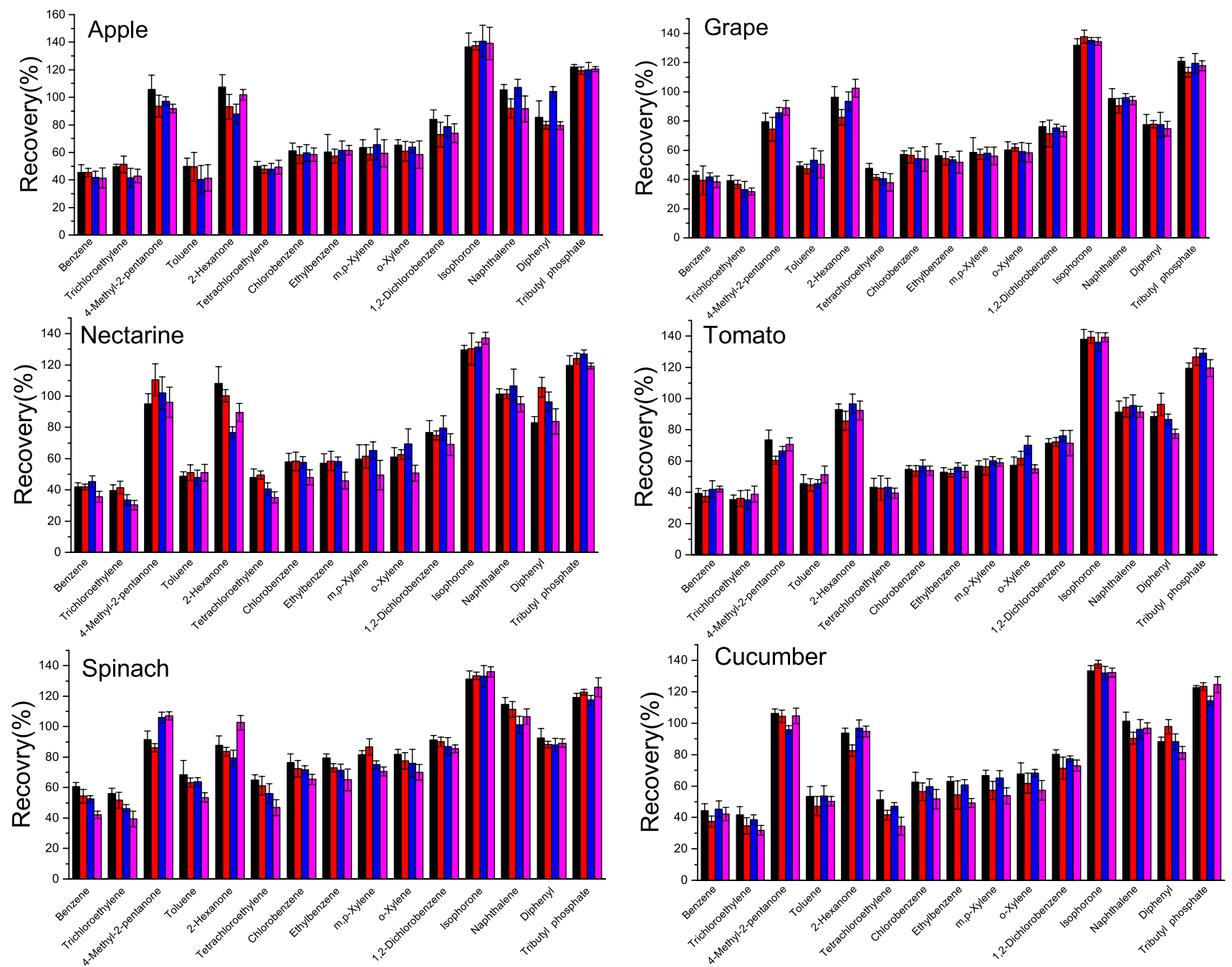

Fig. 1 Recoveries of 16 pesticide adjuvant in different matrices at a spiking level of $0.2 \mathrm{mg} / \mathrm{kg}(n=3)$ using different extraction salts

replicates. Figure 3 shows the effect of different amounts of PSA on the purification of spinach and grape. All targets achieved satisfactory recoveries (ranging from 62.3 to 125.7\%) when $200 \mathrm{mg}$ PSA in combination with $1200 \mathrm{mg}$ $\mathrm{MgSO}_{4}$ used. The recoveries of benzene, trichloroethylene, and tetrachloroethylene in grape and benzene in spinach were less than $60 \%$, but the recoveries of isophorone and tributyl phosphate in spinach and tributyl phosphate in grape were more than $120 \%$ when 100 mg PSA was used. Therefore, $200 \mathrm{mg}$ PSA was chosen as the most cost-effective technique. None of the pesticides adjuvant tested showed any losses even when the amount of PSA was increased to $400 \mathrm{mg}$. So we think that $200 \mathrm{mg}$ PSA was enough to completely remove the matrix co-extractives in all studied matrices.

Until now, the sample pretreatment of QuEChERS method for the determination of the 16 pesticide adjuvant was optimized. Samples were extracted with ACN, $6.0 \mathrm{~g}$ $\mathrm{MgSO}_{4}+1.5 \mathrm{~g} \mathrm{NaAc}$ was used as the extraction salt, and $1200 \mathrm{mg} \mathrm{MgSO}+200 \mathrm{mg}$ PSA was used as the cleanup sorbents. 

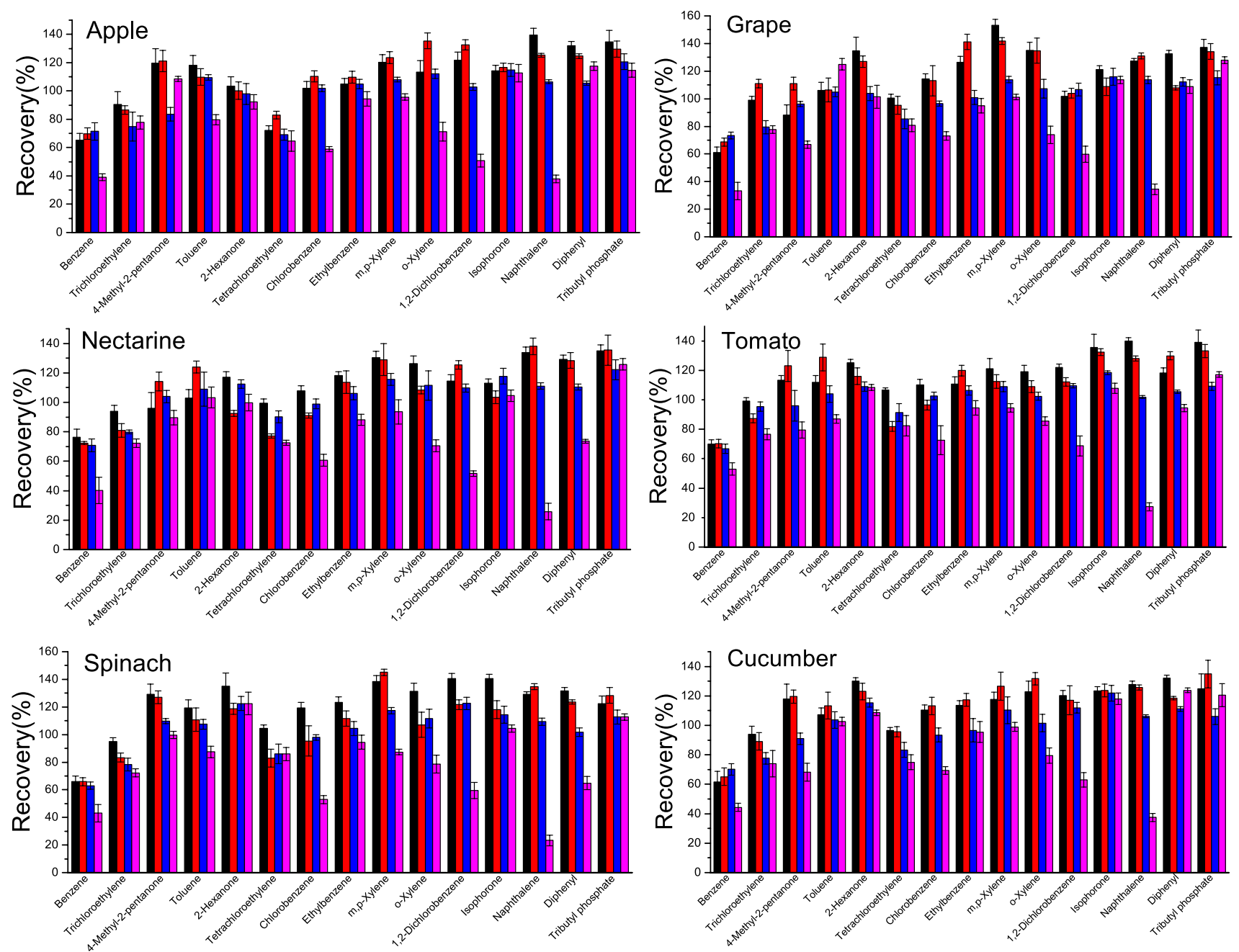

Fig. 2 Recoveries of 16 pesticide adjuvant in different matrices at a spiking level of $0.2 \mathrm{mg} / \mathrm{kg}(n=3)$ using different sorbents

\subsection{Optimization of the chromatographic conditions}

Agilent hp-5 capillary column was used to separate 16 pesticide adjuvants and optimized to achieve minimal run time. The results showed that all pesticide adjuvants except $\mathrm{m}$-xylene and $\mathrm{p}$-xylene could be separated effectively. Although $\mathrm{m}$-xylene and $\mathrm{p}$-xylene cannot be separated, according to relevant standards [28], xylene is generally calculated as the total amount of three substances, so its quantitative calculation can be based on the sum of the three substances.

To achieve satisfactory separation, several gradient temperature programs were examined. The results showed that the initial column temperature was very important for the separation of 16 analytes with low boiling point. A high initial column temperature does not effectively separate the lower boiling components, but if the initial column temperature is too low, the lower boiling components such as benzene will produce severe solvent effect. After continuous attempts, the initial column temperature of $38^{\circ} \mathrm{C}$ can completely separate low boiling point analytes without affecting the benzene peak.

By the splitless mode, solvent peak tailing was serious, so that peak of the early effluent analytes will be covered by the tailing peak of the solvent. Therefore, the split injection mode is adopted. To guarantee sensitivity of all analytes, the lower split ratio is given priority and split ratios of 5:1, 10:1, and 20:1 are tested. It is found that when split ratio is 20:1 the solvent peak tailing phenomenon can be 

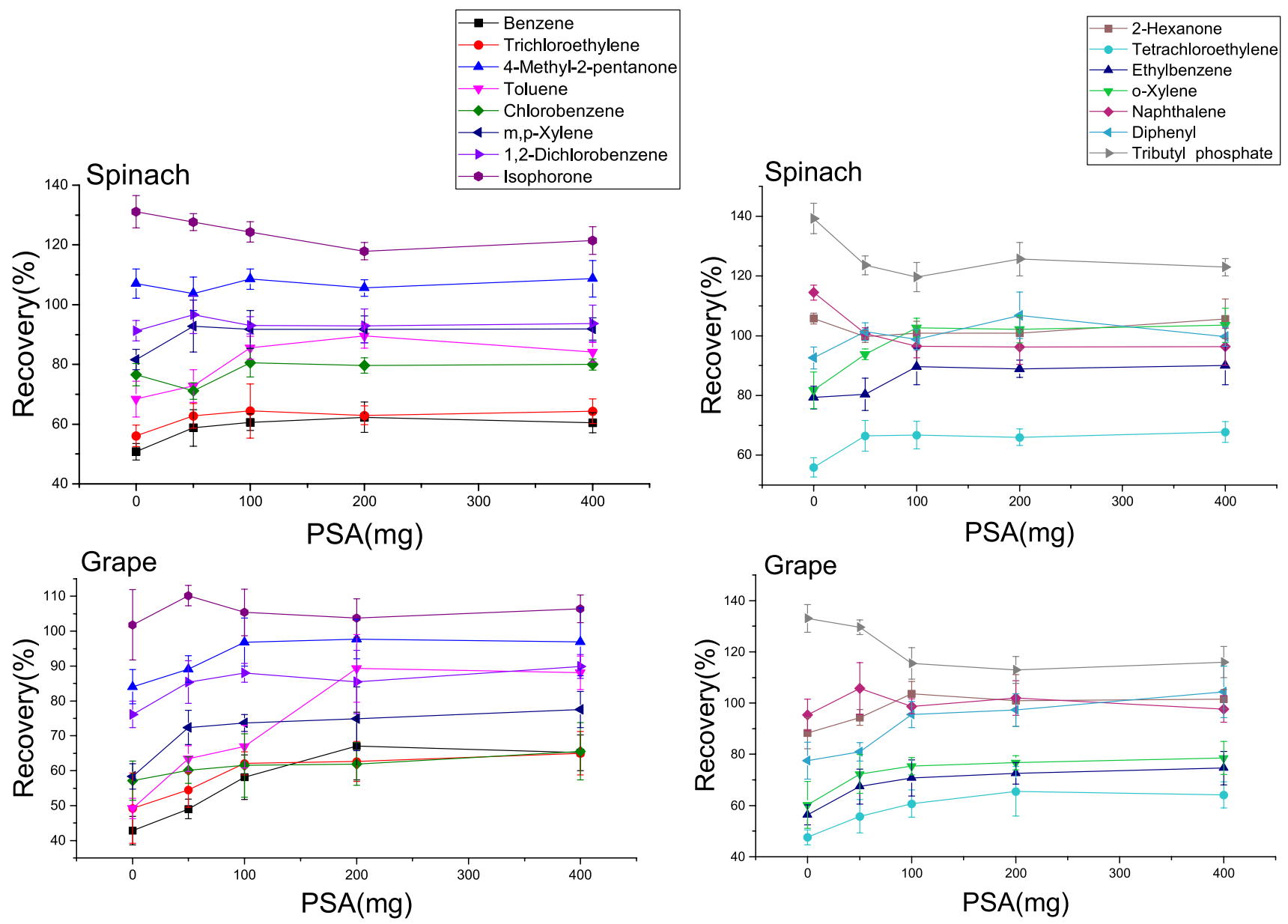

Fig. 3 Recoveries of 16 pesticide adjuvant in spinach and grape at a spiking level of $0.2 \mathrm{mg} / \mathrm{kg}(n=3)$ using different amount of PSA

significantly eliminated and obtain better peak shape. The final chromatograms obtained with the optimized GC-MS program for 16 analytes are shown in Fig. 4.

\subsection{Analytical method validation}

Using the optimized sample preparation conditions, the linearity, accuracy (trueness and precision), sensitivity, and ME of the method were evaluated for analysis of 16 pesticide adjuvants in vegetables (spinach, tomato, cucumber) and fruits (apple, nectarine, grape).

\subsubsection{Linearity, LOD, and LOQ}

Linear regression calculation was carried out with the concentration as the horizontal coordinate and the peak area of the quantitative ion pair as the vertical coordinate. The detection limit (LOD) and quantitative lower limit (LOQ) of the method were determined with three times signal-to-noise ratio $(\mathrm{S} / \mathrm{N}=3)$ and ten times signal-to-noise ratio $(S / N=10)$, respectively. The linear range, correlation coefficient, detection limit, and quantitative limit of different organic solvents are shown in Table 1. Linear ranging from 0.01 to $1.0 \mathrm{mg} / \mathrm{L}$, the correlation coefficients obtained were all greater than 0.995 .

\subsubsection{Accuracy and precision}

The accuracy and precision of the proposed method were assessed by spiking the standards of the studied compounds into tomato, cucumber, spinach, apple, nectarine, and grape at three different levels $(0.1,0.2$, and $0.5 \mathrm{mg} / \mathrm{kg})$ in six replicates. The target compounds were extracted and purified according to the aforementioned procedure 2.2. The accuracy was represented by the mean recovery, and the precision was expressed by the RSD of the recovery values. The details of the method accuracy and precision for all the target compounds in all the tested matrices are given in Table 2. The mean recoveries of 16 pesticide adjuvants at each spiking level fell between 61.2 and $116.3 \%$ in six matrices and the RSDs were $\leq 11.6 \%$. It can be concluded from the recovery experiment that the developed 


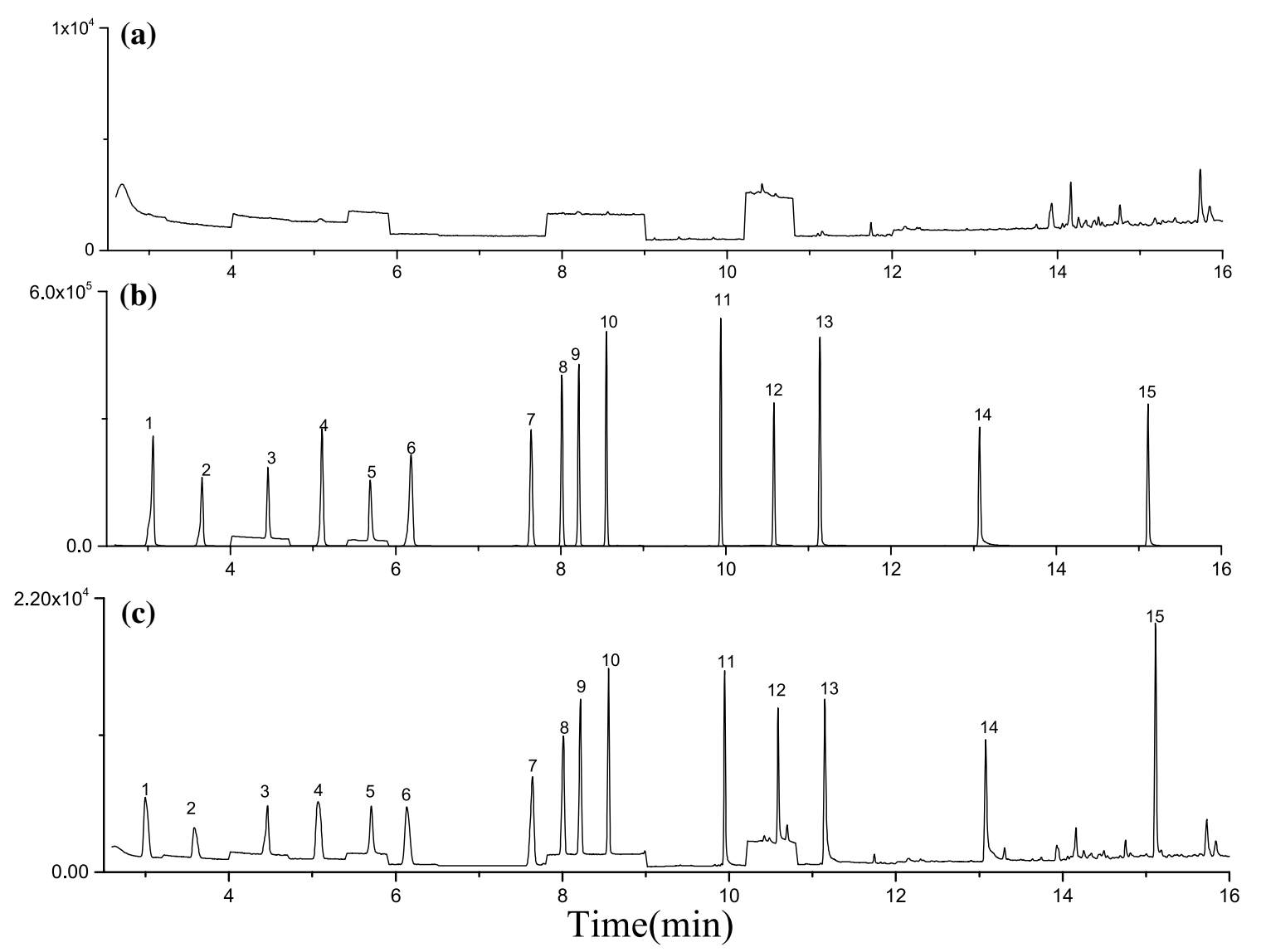

Fig. 4 Typical SIM chromatogram of the 16 analytes. a Blank of spinach; b standard of $2 \mathrm{mg} / \mathrm{L}$ c spiked spinach, spiked concentration: $0.2 \mathrm{mg} / \mathrm{kg}$. Peak identification: 1,Benzene; 2 , trichloroethylene; 3,4-methyl-2-pentanone; 4,toluene; 5,2-hexanone; 6,tetra-

method is fit for the measurement of pesticide adjuvants in real samples like vegetables (spinach, tomato, cucumber) and fruits (apple, nectarine, grape).

\subsubsection{Matrix effect}

Matrix effect was evaluated to determine whether there is a concentration-dependent systematic error due to the matrix, i.e., ion enhancement or ion suppression of the analyte signal caused by the presence of co-extractive and co-occurring matrix components. MEs can be classified into different categories according to the percentage value: soft matrix effect $(|\mathrm{ME}| \leq 20 \%)$, medium matrix effect $(20 \%<|\mathrm{ME}| \leq 50 \%)$, and strong matrix effect $(|\mathrm{ME}|>50 \%$ [29].

Calculated ME values for each analyte in different matrices are presented in Fig. 5. As shown in the figure, slight signal suppression was observed for all analytes in all six matrices except isophorone and naphthalene in apple, tributyl phosphate in tomato cucumber, spinach, and apple. But the ME for all tested analytes in six matrices chloroethylene; 7,chlorobenzene; 8,ethylbenzene; 9,m,p-xylene; 10,0-xylene; 11,1,2-dichlorobenzene; 12,isophorone; 13,naphthalene; 14,diphenyl; 15,tributyl phosphate

were between -14.6 and $+14.5 \%(|\mathrm{ME}| \leq 15.0 \%)$. Carmen Ferrer argues that $|\mathrm{ME}| \leq 20.0 \%$ is considered to have no matrix effect because the variation will be close to the repeatability value [29].

\subsection{Application to market samples}

To confirm the applicability of the validated methods, 30 samples were collected from local supermarket in Chongqing (China) and were analyzed by the method. Samples were analyzed as described in the sample preparation method section. The results showed that most of the pesticides adjuvants were undetected from the 30 actual samples. Naphthalene was detected in four samples with concentrations at $0.022-0.061 \mathrm{mg} / \mathrm{kg}$. Toluene was detected at the concentration of $0.036 \mathrm{mg} / \mathrm{kg}$ in one sample, while xylenes and 1,2-dichlorobenzene were also detected at the concentration of $0.011 \mathrm{mg} / \mathrm{kg}$ and $0.017 \mathrm{mg} / \mathrm{kg}$ respective in the same sample. The results of actual samples were similar to those of Wang Shanshan et al. They found that the toluene levels in market are produced in 
Table 2 Mean recoveries (\%) and relative standard deviations (RSD, \%) of 16 pesticide adjuvant in tomato, cucumber, spinach, apple, nectarine, and grape at three fortification levels $(n=6)$

\begin{tabular}{|c|c|c|c|c|c|c|c|}
\hline \multirow[t]{2}{*}{ Analyte } & \multirow{2}{*}{$\begin{array}{l}\text { Spiked (mg/ } \\
\mathrm{kg})\end{array}$} & \multicolumn{6}{|c|}{ Recovery (RSD) (\%) $(n=6)$} \\
\hline & & Tomato & Cucumber & Spinach & Apple & Nectarine & Grape \\
\hline \multirow[t]{3}{*}{ Benzene } & 0.1 & $73.6(4.1)$ & $64.0(3.3)$ & $63.8(4.9)$ & $61.2(2.9)$ & $71.5(7.2)$ & $71.0(5.7)$ \\
\hline & 0.2 & $78.5(2.4)$ & $70.7(5.2)$ & $60.8(3.8)$ & $70.5(2.9)$ & $73.4(6.0)$ & $64.6(1.0)$ \\
\hline & 0.5 & $85.3(4.8)$ & $81.0(3.3)$ & $79.8(3.1)$ & $85.5(3.3)$ & $81.8(3.9)$ & $77.6(4.3)$ \\
\hline \multirow[t]{3}{*}{ Trichloroethylene } & 0.1 & $70.3(2.9)$ & $62.4(3.4)$ & $67.0(4.7)$ & $69.3(2.3)$ & $70.3(5.5)$ & $69.4(3.8)$ \\
\hline & 0.2 & $71.8(2.0)$ & $70.4(10.2)$ & $69.8(9.8)$ & $70.2(3.0)$ & $83.1(5.9)$ & $76.4(1.2)$ \\
\hline & 0.5 & $86.5(8.8)$ & $80.8(3.1)$ & $79.8(2.9)$ & $86.1(3.2)$ & $82.8(3.8)$ & $69.8(4.6)$ \\
\hline \multirow[t]{3}{*}{ 4-Methyl-2-pentanone } & 0.1 & $102.4(7.4)$ & $100.8(7.6)$ & $100.4(10.7)$ & $69.5(10.5)$ & $98.7(10.1)$ & $86.2(10.6)$ \\
\hline & 0.2 & $85.3(10.4)$ & $96.6(2.8)$ & $92.9(8.4)$ & $72.8(10.5)$ & $86.5(4.4)$ & $76.7(6.4)$ \\
\hline & 0.5 & $80.8(4.0)$ & $99.5(2.6)$ & $104.2(4.0)$ & $89.8(4.5)$ & $92.0(3.9)$ & $92.6(4.1)$ \\
\hline \multirow[t]{3}{*}{ Toluene } & 0.1 & $81.8(2.4)$ & $81.9(4.9)$ & $82.4(9.9)$ & $82.1(2.9)$ & $85.6(10.4)$ & $82.6(8.9)$ \\
\hline & 0.2 & $91.5(5.9)$ & $95.6(6.7)$ & $91.8(10.2)$ & $99.9(5.4)$ & $91.9(5.9)$ & $98.2(6.1)$ \\
\hline & 0.5 & $95.7(6.1)$ & $93.7(5.2)$ & $94.6(5.1)$ & $92.8(7.6)$ & $92.8(5.9)$ & $91.2(5.9)$ \\
\hline \multirow[t]{3}{*}{ 2-Hexanone } & 0.1 & $107.3(6.1)$ & $110.6(8.2)$ & $110.6(7.3)$ & $103.7(2.2)$ & $99.9(8.7)$ & $113.8(3.8)$ \\
\hline & 0.2 & $100.9(6.6)$ & $108.5(4.9)$ & $109.6(4.7)$ & $93.1(5.7)$ & $99.3(3.6)$ & $103.6(2.1)$ \\
\hline & 0.5 & $96.5(3.4)$ & $98.1(3.1)$ & $101.9(5.3)$ & $98.6(3.1)$ & $106.5(1.9)$ & $100.6(2.8)$ \\
\hline \multirow[t]{3}{*}{ Tetrachloroethylene } & 0.1 & $72.6(2.6)$ & $65.2(3.3)$ & $66.2(3.2)$ & $72.8(1.6)$ & $74.4(3.5)$ & $68.0(2.9)$ \\
\hline & 0.2 & $74.6(1.6)$ & $75.8(11.6)$ & $79.4(3.4)$ & $79.0(3.3)$ & $86.9(5.0)$ & $76.4(1.4)$ \\
\hline & 0.5 & $85.1(5.0)$ & $83.0(6.1)$ & $83.9(2.5)$ & $87.0(6.0)$ & $83.6(3.5)$ & $82.9(4.0)$ \\
\hline \multirow[t]{3}{*}{ Chlorobenzene } & 0.1 & $85.5(3.8)$ & $81.9(3.3)$ & $83.3(4.9)$ & $85.8(3.8)$ & $85.9(4.8)$ & $83.4(3.6)$ \\
\hline & 0.2 & $86.5(3.2)$ & $86.1(3.8)$ & $87.6(4.4)$ & $94.1(3.3)$ & $97.4(5.9)$ & $88.0(1.8)$ \\
\hline & 0.5 & $90.3(3.8)$ & $88.1(3.5)$ & $90.4(2.4)$ & $91.8(2.6)$ & $94.0(3.4)$ & $92.9(3.4)$ \\
\hline \multirow[t]{3}{*}{ Ethylbenzene } & 0.1 & $89.5(5.6)$ & $88.3(3.8)$ & $84.9(10.2)$ & $80.3(5.1)$ & $91.2(7.0)$ & $92.2(7.7)$ \\
\hline & 0.2 & $96.9(2.7)$ & $92.5(5.1)$ & $93.2(5.2)$ & $95.4(3.6)$ & $99.2(3.2)$ & $91.8(2.5)$ \\
\hline & 0.5 & $93.5(4.2)$ & $90.7(3.8)$ & $91.5(2.7)$ & $95.1(3.1)$ & $96.2(4.3)$ & $92.7(4.4)$ \\
\hline \multirow[t]{3}{*}{ m,p-Xylene } & 0.1 & $93.0(8.1)$ & $84.6(5.4)$ & $98.1(4.6)$ & $99.9(7.1)$ & $107.7(9.5)$ & $92.1(10.9)$ \\
\hline & 0.2 & $94.7(3.7)$ & $101.5(6.3)$ & 109.5 (6.6) & $97.3(4.6)$ & $93.0(9.1)$ & $96.8(4.1)$ \\
\hline & 0.5 & $98.7(4.2)$ & $95.9(4.3)$ & $97.5(3.1)$ & $101.4(3.5)$ & $103.4(5.0)$ & $89.7(5.2)$ \\
\hline \multirow[t]{3}{*}{ o-Xylene } & 0.1 & $95.1(5.8)$ & $88.7(5.3)$ & $92.5(9.6)$ & $87.3(4.3)$ & $103.1(7.2)$ & $91.8(11.6)$ \\
\hline & 0.2 & $97.4(3.4)$ & $90.5(5.1)$ & $99.9(5.2)$ & $91.7(4.0)$ & $96.7(6.7)$ & $92.0(2.7)$ \\
\hline & 0.5 & $94.1(3.9)$ & $92.7(3.7)$ & $93.7(2.6)$ & $96.9(2.7)$ & $99.8(4.2)$ & $97.2(4.1)$ \\
\hline \multirow[t]{3}{*}{ 1,2-Dichlorobenzene } & 0.1 & $86.2(2.3)$ & $87.0(2.2)$ & $101.9(2.8)$ & $96.1(2.4)$ & $100.8(4.2)$ & $93.1(2.9)$ \\
\hline & 0.2 & $86.3(4.1)$ & $97.4(2.2)$ & $102.1(3.4)$ & $94.9(2.8)$ & $101.6(3.6)$ & $93.0(2.8)$ \\
\hline & 0.5 & $96.8(2.6)$ & $95.5(3.4)$ & $96.9(1.1)$ & $96.4(1.5)$ & $105.4(2.1)$ & $94.0(1.9)$ \\
\hline \multirow[t]{3}{*}{ Isophorone } & 0.1 & $111.9(3.6)$ & $111.6(4.7)$ & $113.8(5.6)$ & $114.9(8.9)$ & $106.6(9.8)$ & $111.8(3.7)$ \\
\hline & 0.2 & $110.6(4.6)$ & $112.9(3.0)$ & $116.2(3.5)$ & $110.5(2.3)$ & $116.4(3.6)$ & $108.7(5.7)$ \\
\hline & 0.5 & $100.8(3.0)$ & $110.8(2.6)$ & $110.9(1.3)$ & $115.4(1.3)$ & $115.0(3.4)$ & $111.7(2.7)$ \\
\hline \multirow[t]{3}{*}{ Naphthalene } & 0.1 & $107.4(1.1)$ & $102.6(1.5)$ & $99.6(2.1)$ & $99.7(2.4)$ & $111.2(5.3)$ & $113.6(3.0)$ \\
\hline & 0.2 & $108.2(5.0)$ & $113.7(1.4)$ & $103.4(2.4)$ & $106.1(1.7)$ & $119.0(4.3)$ & $111.2(5.4)$ \\
\hline & 0.5 & $105.6(1.3)$ & $107.6(3.4)$ & $102.7(2.2)$ & $101.0(1.1)$ & $115.0(2.8)$ & $109.8(2.1)$ \\
\hline \multirow[t]{3}{*}{ Diphenyl ether } & 0.1 & $96.7(1.6)$ & $98.1(1.2)$ & $106.5(2.3)$ & $105.6(3.6)$ & $106.5(2.1)$ & $103.2(1.4)$ \\
\hline & 0.2 & $97.9(4.3)$ & $103.6(1.6)$ & $101.7(2.6)$ & $110.7(2.7)$ & $108.0(1.1)$ & $100.3(4.0)$ \\
\hline & 0.5 & $94.1(1.5)$ & $91.9(4.1)$ & $95.6(6.8)$ & $105.1(1.1)$ & $104.6(1.5)$ & $107.2(2.8)$ \\
\hline \multirow[t]{3}{*}{ Tributyl phosphate } & 0.1 & $111.9(5.7)$ & $116.3(5.4)$ & $113.9(4.2)$ & $110.3(8.5)$ & $109.4(10.2)$ & $111.1(10.3)$ \\
\hline & 0.2 & $114.6(8.1)$ & $115.6(1.9)$ & $113.4(3.8)$ & $119.6(4.4)$ & $116.5(9.3)$ & $109.9(6.7)$ \\
\hline & 0.5 & $112.2(5.5)$ & $114.5(7.2)$ & $113.4(2.1)$ & $117.8(2.7)$ & $109.5(5.3)$ & $112.5(3.9)$ \\
\hline
\end{tabular}


Fig. 5 Matrix effect (ME) of each studied analyte in the six matrices (tomato, cucumber, spinach, apple, nectarine, and grape)

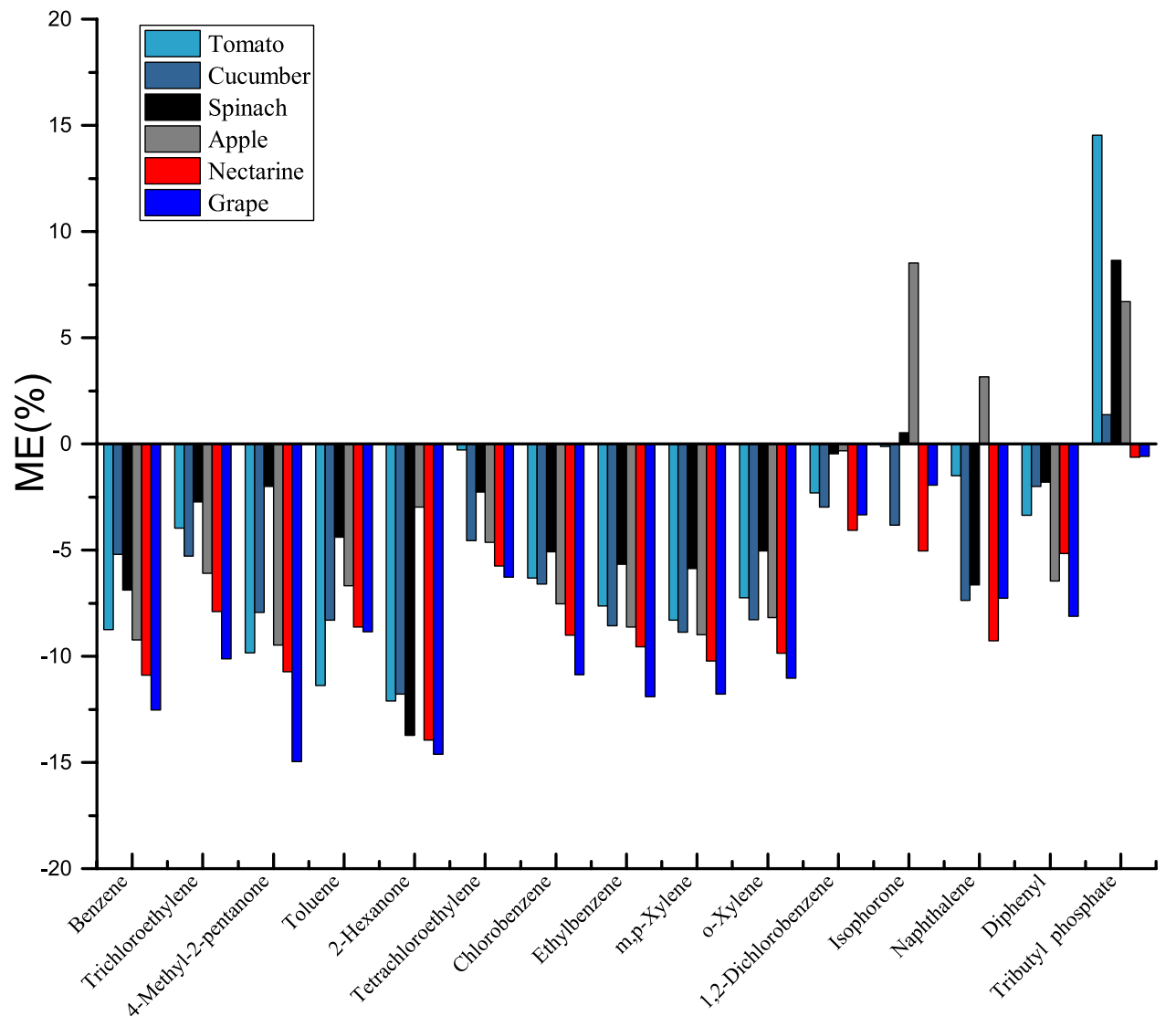

the range 0.015 to $0.035 \mathrm{mg} / \mathrm{kg}$ and xylenes with values $0.014-0.020 \mathrm{mg} / \mathrm{kg}[17]$.

\section{Conclusions}

In this study, a modified QuEChERS method coupled with GC-MS separation and detection was developed for the simultaneous determination of 16 pesticide adjuvants in vegetables (spinach, tomato, cucumber) and fruits (apple, nectarine, grape). Both extraction, cleanup procedures of QuEChERS method and GC-MS parameters were discussed and optimized. Finally, the method was validated in terms of linearity, recovery, precision, LOD, LOQ, and ME. Recoveries of the tested 16 pesticide adjuvants were between $61.2 \%$ and $116.3 \%$, and RSDs were consistently $\leq 11.6 \%$. It is worth noting that the ME value of this method is very low and can be ignored $(|\mathrm{ME}| \leq 15.0 \%)$. The method is useful for obtaining high-risk pesticide adjuvants residue data to evaluate the use of harmful pesticide adjuvants, to guide the rational use of pesticide adjuvants and provide scientific support for scientific supervision.

Acknowledgements This work was supported by the Chongqing scientific research institute performance incentive and guidance special project (cstc2017jxjl0144).

\section{Compliance with ethical standards}

Conflict of interest The authors have declared no conflicts of interest.

\section{References}

1. Mesnage R, Antoniou MN (2017) Ignoring adjuvant toxicity falsifies the safety profile of commercial pesticides. Front Public Health 5:361. https://doi.org/10.3389/fpubh.2017.00361

2. Li H, Jiang ZJ, Cao XL, Su H, Shao H, Jin F, Zheng LF, Abd El-Aty AM, Wang J (2017) SPE/GC-MS determination of 2-Pyrrolidone, $\mathrm{N}$-Methyl-2-pyrrolidone, and N-Ethyl-2-pyrrolidone in liquid pesticide formulations. Chromatographia 81:359-364. https:// doi.org/10.1007/s10337-017-3435-7

3. Mesnage R, Bernay B, Seralini GE (2013) Ethoxylated adjuvants of glyphosate-based herbicides are active principles of human cell toxicity. Toxicology 313:122-128. https://doi.org/10.1016/j. tox.2012.09.006

4. Mesnage R, Defarge N, Spiroux de Vendomois J, Seralini GE (2014) Major pesticides are more toxic to human cells than their declared active principles. Biomed Res Int 2014:179691. https:// doi.org/10.1155/2014/179691

5. Beggel S, Werner I, Connon RE, Geist JP (2010) Sublethal toxicity of commercial insecticide formulations and their active ingredients to larval fathead minnow (Pimephales promelas). Sci Total Environ 408:3169-3175. https://doi.org/10.1016/j.scito tenv.2010.04.004

6. Mansano AS, Moreira RA, Pierozzi M, Oliveira TMA, Vieira EM, Rocha O, Regali-Seleghim MH (2016) Effects of diuron and 
carbofuran pesticides in their pure and commercial forms on Paramecium caudatum: the use of protozoan in ecotoxicology. Environ Pollut 213:160-172. https://doi.org/10.1016/j.envpo I.2015.11.054

7. Institute for the Control of Agrochemicals (2015) A consultation paper on prohibited and restricted lists of pesticide adjuvants. http://www.chinapesticide.gov.cn/zwtz/755.jhtml. (in Chinese)

8. IARC (2019) Agents classified by the IARC monographs, volumes 1-123. https://monographs.iarc.fr/agents-classified-by-the-iarc/

9. Khan MA, Brown CD (2016) Influence of commercial formulation on leaching of four pesticides through soil. Sci Total Environ 573:1573-1579. https://doi.org/10.1016/j.scitotenv.2016.09.076

10. Surgan M, Condon M, Cox C (2010) Pesticide risk indicators: unidentified inert ingredients compromise their integrity and utility. Environ Manag 45:834-841. https://doi.org/10.1007/s0026 7-009-9382-9

11. Viel J-F, Rouget F, Warembourg C, Monfort C, Limon G, Cordier $S$, Chevrier C (2017) Behavioural disorders in 6-year-old children and pyrethroid insecticide exposure: the PELAGIE motherchild cohort. Occup Environ Med 74:275-281. https://doi. org/10.1136/oemed-2016-104035

12. Chen J, Fine JD, Mullin CA (2018) Are organosilicon surfactants safe for bees or humans? Sci Total Environ 612:415-421. https ://doi.org/10.1016/j.scitotenv.2017.08.175

13. Fine JD, Mullin CA, Frazier MT, Reynolds RD (2017) Field residues and effects of the insect growth regulator novaluron and its major Co-formulant N-Methyl-2-Pyrrolidone on honey bee reproduction and development. J Econ Entomol 110:1993-2001. https://doi.org/10.1093/jee/tox220

14. Peng F, Ji W, Zhu F, Peng D, Yang M, Liu R, Pu Y, Yin L (2016) A study on phthalate metabolites, bisphenol A and nonylphenol in the urine of Chinese women with unexplained recurrent spontaneous abortion. Environ Res. https://doi.org/10.1016/j. envres.2016.04.003

15. Li X, Ying GG, Zhao JL, Chen ZF, Lai HJ, Su HC (2013) 4-Nonylphenol, bisphenol-A and triclosan levels in human urine of children and students in China, and the effects of drinking these bottled materials on the levels. Environ Int 52:81-86. https://doi. org/10.1016/j.envint.2011.03.026

16. Geens T, Neels H, Covaci A (2012) Distribution of bisphenol-A, triclosan and n-nonylphenol in human adipose tissue, liver and brain. Chemosphere 87:796-802. https://doi.org/10.1016/j. chemosphere.2012.01.002

17. Qi Y, Ma C, Wan MF, Liu ZD, Zheng LF, Jin F, Jin MJ, She YX, Wang J, Wang SS (2019) Multiresidue determination of six pesticide adjuvants in characteristic minor crops using QuEChERS method and gas chromatography-mass spectrometry. ChemistrySelect 4:66-70. https://doi.org/10.1002/slct.201803328

18. Jiang ZJ, Cao XL, Li H, Zhang C, Abd El-Aty AM, Jin F, Shao H, Jin MJ, Wang SS, She YX, Wang J (2017) Fast determination of alkylphenol ethoxylates in leafy vegetables using a modified quick, easy, cheap, effective, rugged, and safe method and ultrahigh performance supercritical fluid chromatography-tandem mass spectrometry. J Chromatogr A 1525:161-172. https://doi. org/10.1016/j.chroma.2017.10.035

19. Luo L, Yang Y, Wang Q, Li H-P, Luo Z-F, Qu Z-P, Yang Z-G (2017) Determination of 4- $\mathrm{n}$-octylphenol, 4- $\mathrm{n}$-nonylphenol and bisphenol $A$ in fish samples from lake and rivers within Hunan Province, China. Microchem J 132:100-106. https://doi. org/10.1016/j.microc.2017.01.012

20. Li H, Jiang Z, Cao X, Su H, Shao H, Jin F, Abd El-Aty AM, Wang $J$ (2017) Simultaneous determination of three pesticide adjuvant residues in plant-derived agro-products using liquid chromatography-tandem mass spectrometry. J Chromatogr A 1528:53-60. https://doi.org/10.1016/j.chroma.2017.10.075

21. Michel A, Brauch HJ, Worch E, Lange FT (2012) Development of a liquid chromatography tandem mass spectrometry method for trace analysis of trisiloxane surfactants in the aqueous environment: an alternative strategy for quantification of ethoxylated surfactants. J Chromatogr A 1245:46-54

22. Chen J, Mullin CA (2013) Quantitative determination of trisiloxane surfactants in beehive environments based on liquid chromatography coupled to mass spectrometry. Environ Sci Technol 47:9317-9323. https://doi.org/10.1021/es4010619

23. Anastassiades M, Lehotay SJ, Štajnbaher D, Schenck FJ (2003) Fast and easy multiresidue method employing acetonitrile extractionpartitioning and "dispersive solid-phase extraction" for the determination of pesticide residues in produce. J AOAC Int 86:412-431

24. Lehotay SJ, Mastovska K, Lightfield AR, Gates RA (2010) Multianalyst, multi-matrix performance of the QuEChERS approach for pesticide residues in foods and feeds using HPLC/MS/ MS analysis with different calibration techniques. J AOAC Int 93:355-367

25. González-Curbelo MÁ, Socas-Rodríguez B, Herrera-Herrera AV González-Sálamo J, Hernández-Borges J, Rodríguez-Delgado MÁ (2015) Evolution and applications of the QuEChERS method. Trends Anal Chem 71:169-185. https://doi.org/10.1016/j. trac.2015.04.012

26. Lehotay SJ (2007) Determination of pesticide residues in foods by acetonitrile extraction and partitioning with magnesium sulfate: collaborative study. J AOAC Int 90:485-520

27. Yang RZ, Wang JH, Wang ML, Zhang R, Lu XY, Liu WH (2011) Dispersive solid-phase extraction cleanup combined with accelerated solvent extraction for the determination of carbamate pesticide residues in radix glycyrrhizae samples by UPLC-MSMS. J Chromatogr Sci 49:702-708. https://doi.org/10.1093/chrsc $\mathrm{i} / 49.9 .702$

28. U. S. Environmental Protection Agency (1995) Volatile organic compounds in water by purge and trap capillary column gas chromatography with photoionization and electrolytic conductivity detectors in series. Revision 21. EPA Method 502.2

29. Ferrer C, Lozano A, Aguera A, Giron AJ, Fernandez-Alba AR (2011) Overcoming matrix effects using the dilution approach in multiresidue methods for fruits and vegetables. J Chromatogr A 1218:7634-7639. https://doi.org/10.1016/j.chroma.2011.07.033

Publisher's Note Springer Nature remains neutral with regard to jurisdictional claims in published maps and institutional affiliations. 